\title{
Hepatitis B, Hepatitis C and HIV in Pregnant Women in the Community in the Democratic Republic of Congo
}

\author{
Jeff Maotela Kabinda ${ }^{1,2,3}$, Tony Shindano Akilimali², Ahuka Serge Miyanga ${ }^{1}$, \\ Philippe Donnen4,5,6, Dramaix-Wilmet Michèle ${ }^{3,4,5}$ \\ ${ }^{1}$ Provincial Blood Transfusion Centre of Bukavu, Bukavu, Congo \\ ${ }^{2}$ Catholic University of Bukavu, Bukavu, Congo \\ ${ }^{3}$ Research Centre in Biostatistics and Epidemiology, Brussels, Belgium \\ ${ }^{4}$ Free University of Brussels, Brussels, Belgium \\ ${ }^{5}$ School of Public Health, Brussels, Belgium \\ ${ }^{6}$ Centre for Policy and Health Systems/International Health, Brussels, Belgium \\ Email: kabindaalu@yahoo.fr
}

Received 6 May 2015; accepted 12 June 2015; published 15 June 2015

Copyright (C) 2015 by authors and Scientific Research Publishing Inc.

This work is licensed under the Creative Commons Attribution International License (CC BY).

http://creativecommons.org/licenses/by/4.0/

(c) (i) Open Access

\begin{abstract}
Objectives: To determine the prevalence of HBV, HCV and HIV in pregnant women and identify risk factors. Materials and Methods: Descriptive and analytical study on pregnant women in the community Maniema (DRC) between 24 June and 24 July 2013. We enrolled a total of 581 pregnant women. Results: Prevalence among pregnant women was $4.1 \%$ (2.5\% to $6.3 \%)$ for HIV, $5.9 \%$ (3.9\% to $8.4 \%)$ for the HBsAg and $4.1 \%(2.5 \%$ to $6.4 \%)$ for hepatitis C. The risk factor was for HIV, blood transfusion history in women. For HBsAg the main risk factor was the tattoo history and no statistically significant factor was found for hepatitis C. Conclusion: To reduce the risk of transmission of hepatitis from mother to child, all pregnant women should be screened prenatally. A strengthening of routine screening of blood products must be done and a health education of the population on the mode of contamination should be conducted.
\end{abstract}

Keywords

HBV, HCV, HIV, Pregnancy, Risk Factors

\section{Introduction}

Viral infections in pregnant women are responsible for morbidity and mortality proven in the mother-child pair

How to cite this paper: Kabinda, J.M., Akilimali, T.S., Miyanga, A.S., Donnen, P. and Michèle, D.-W. (2015) Hepatitis B, Hepatitis C and HIV in Pregnant Women in the Community in the Democratic Republic of Congo. World Journal of AIDS, 5, 124-130. http://dx.doi.org/10.4236/wja.2015.52015 
[1]. Viral hepatitis is the leading cause of acute or chronic liver disease worldwide. The chronicity is even more common than infection occurs at an early age, especially in cases of neonatal contamination mainly for hepatitis B [2] [3]. This chronic infection is the leading provider of cirrhosis, liver failure and hepatocellular carcinoma, causes of early death among children. Vertical transmission of HBV is prevented by vaccination with efficiency greater than $90 \%$ while no vaccine is available for HCV. Viral hepatitis B, C and HIV infection is a worldwide public health problem [4]-[6]. The global prevalence is distributed as follows: 5.4\% for HBV, $1 \%$ for HIV infection and 3\% for hepatitis C [2] [7]. Viral hepatitis B and C have a ubiquitous but irregular distribution thus drawing the world into small area ( $<2 \%$ for $\mathrm{HBV}$ and between $1 \%$ to $2.5 \%$ for $\mathrm{HCV}$ ), intermediate ( $2 \%$ - $7 \%$ for HBV and 2.5 to $10 \%$ for HCV) and high endemicity (> 8\% for HBV and $>10 \%$ for HCV) [8]-[10]. In theory, the Democratic Republic of Congo (DRC) is a country of high endemicity area for hepatitis B and C. According to recent data in the country among blood donors, the overall seroprevalence of HIV, HBV and HCV was respectively $2.9 \%, 1.6 \%, 0.2 \%$ [10], but there is no published data in pregnant women. Yet a better knowledge of the epidemiology of these viruses is important to enable early identification of its magnitude and the main risk factors in the group of pregnant women in order to assess the level of risk of vertical transmission and to take specific measures. The aim of our study was to determine the seroprevalence of HBV HCV and HIV in pregnant women and to identify potential risk factors.

\section{Methodology}

\subsection{Framework of the Study}

This is a transversal study referred to descriptive and analytical in pregnant women during the period from 24 June to 24 July 2013, conducted in the two health zones of the city of Kindu in the Democratic Republic of Congo (zones Health Kindu and Alunguli) and two rural areas (Kasongo and Kunda). These four health areas include 46 health areas in total; 33 easily accessible health areas were the subject of the investigation. These four areas were chosen because of the presence of the program for the prevention of transmission from mother to child of HIV and geographical accessibility. Kindu is the capital of Maniema province while other health areas within the province, it is the Central East of the Democratic Republic of Congo. This province is one of 11 provinces of the DRC. It has an area equal to 132,250 square kilometers and 2,038,471 inhabitants, with a density of 15 inhabitants $/ \mathrm{km}^{2}$. Maniema is divided into 18 health zones responsible for providing primary health care to the population, and assistance of 1st and 2nd level health facilities. These areas have a total of 274 health areas. However, in general, the proportion of health centers offering a minimum package of comprehensive activities is low. The general referral hospitals are under-equipped and quality of complementary package of activities offered by these hospitals do not meet national standards.

\subsection{Study Population}

We conducted a survey of households. We made the calculation of the number of households approximately deduct the number of pregnant women hoping to have at least one pregnant woman per household. The size of the calculated sample was of 324 based on a proportion of pregnant women with HIV to 3.5\% nationally [11] and an accuracy of $2 \%$. After multiplication by a sampling effect of two, a total of 648 households was included. The first step was to decide to households in 33 clusters (health area), each cluster containing at least 20 households. A selection of health areas (cluster) on the basis of a list of all the health areas of the 4 health zones that had been drawn up in alphabetical order was carried out with probability proportional to the population size of the areas health. The second step was to make a selection of villages/streets in the health areas selected in the first stage. After drawing up an alphabetical list of villages or avenues, a random draw proportional to the size of the population of the villages/avenues was performed on average 4 villages/streets by health area were included. Thus 138 villages were selected representing $12 \%$ of all villages/streets. The number of households to be surveyed in the villages/avenues selected was obtained by dividing the number of required households ( 20 households) by the number of avenues/villages selected. The investigation team consisted of 4 people per health area: the supervising physician, a nurse, a laboratory technician and a plot of reliever recruited in the community. The investigation team visited the village center/avenues selected and chose a direction at random following the pen tip tossed and applied a systematic sampling type: in the selected travel direction The first household was the one that matched the random number drawn between 1 and the sampling interval was determined by the number 
of households in the village (known in advance by the plot reliever) on the number of households to be surveyed. The selection thus increased from household to household by adding the sampling interval $\mathrm{k}$ in the household corresponding number last visited up to the number of households required for this village/this avenue. From this set we selected households that had a pregnant wife and that the latter had freely agreed to participate in the survey. So we have reached a total of 581 pregnant women, the proportion of non-respondents less than $1 \%$. The following parameters were studied: age of the woman, the woman's level of education, marital status, place of origin of women, history of blood transfusion or tattooing/scarification, total number of pregnancies, age pregnancy, husband's occupation, level of education of the husband, serology results of HBV, HIV and HCV.

Aspects ethics were complied in sens, the study participation was voluntary after a clear explanation and verbal approval was obtained.

\subsection{Serology}

Serodiagnosis on each sample was taken from the following reagents: a) HBV: HBsAg DetermineTM, Inverness Medical Japan Ltd.; b) HCV: Orgenics Ltd, Medical Innovations Group, Israel c) HIV: DetermineTM HIV-1/2 Abbott. A blood sample was collected in a coded tube without anticoagulant and kept at room temperature. After complete coagulation, it was centrifuged to settle the serum. We used e rapid test for screening anti-HIV1/2 antibodies, for detecting the surface antigen of hepatitis B (AgHbs) virus and for the detection of hepatitis $\mathrm{C}$ virus antibodies.

\subsection{Statistical Analysis}

Data were coded using the SPSS Version 20 software. Some variables were transformed for analysis. The age of the pregnant woman was grouped into 4 categories (20 years or younger, between 21 and 30, between 31 and 40 and 41 and over), marital status was presented in 4 categories (single, common-law, married and separated/widowed/divorced) for description but dichotomized for the bivariate analysis (couple lives and living alone), the level of women's education was categorized into 3 groups (without primary, secondary/university), the level of education of the husband into four groups (without primary, secondary, higher) and occupation of husband into 3 groups (without, private and state's official) for the sample description and the following analyzes, into two groups: without/official and private.

Descriptive analysis was made as proportions for categorical variables, median, minimum and maximum for the age of the woman, age of pregnancy and the number of pregnancies. To analyze the association between the presence of viral markers and potential risk factors the chi-square test of Pearson was applied, the chi-square trend was applied in the case of increasing or decreasing proportions according to categories ordered. Odds ratios (OR) and their 95\% confidence intervals (95\% CIs) were calculated. The Fisher exact test was used when the conditions for application of the chi-square test of Pearson were not met. The statistical significance chosen was $\mathrm{p}<0.05$.

\section{Results}

\subsection{Presentation of the Sample}

Seventy-three percent of pregnant women who participated in the study were age less than 30 years. The median age of women in the sample was 25 years and in $81 \%$ of cases, these women were married. They lived mainly in rural areas (79\%) and $24 \%$ of them had never been to school. In terms of personal history, $6.5 \%$ had a tattoo or scarification and $7 \%$ had received a blood transfusion in the last delivery. The median age of the current pregnancy and the total number of pregnancies were 5 months and 3 pregnancies respectively. As for the husband of pregnant women, $17 \%$ had not done a study and $3 \%$ were unemployed (Table 1).

\subsection{Prevalence and Determinants of HIV, HBV and HCV in Pregnant Women}

HIV prevalence was higher than that of the entire sample (4.1\% with a 95\% CI 2.5\% to 6.3\%) in the group of women with a history of transfusion (15.6\%), pregnant from the urban areas $(7.0 \%)$, women whose husband had a primary level of education (8.1\%) or secondary (5.0\%). However the only variable associated with statistically significantly with the presence of HIV was the transfusion history $(p=0.02)$ as shown in Table 2 . The 
Table 1. General profile of the pregnant woman in the Maniema province in 2013.

\begin{tabular}{|c|c|c|c|}
\hline & $\mathbf{n}$ & $\%$ & Median (min-max) \\
\hline Age (in years) & 579 & & $25(15-48)$ \\
\hline$<20$ & & 27.2 & \\
\hline $21-30$ & & 45.3 & \\
\hline $31-40$ & & 23.4 & \\
\hline 41 et plus & & 4.2 & \\
\hline Marital status & 578 & & \\
\hline Single & & 8.1 & \\
\hline Union & & 6.7 & \\
\hline Married & & 80.6 & \\
\hline Separated/widowed/divorced & & 4.5 & \\
\hline Women's Studies level & 575 & & \\
\hline Primary & & 36 & \\
\hline Higher Secondary & & 40.2 & \\
\hline Without & & 23.8 & \\
\hline Woman original middle & 581 & & \\
\hline Urban & & 21.2 & \\
\hline Rural & & 78.8 & \\
\hline Pregnancies & 524 & & $3(1-14)$ \\
\hline Age of pregnancy in months & 524 & & $5(1-10)$ \\
\hline Transfusion history at last birth & 520 & 6.9 & \\
\hline Husband study level & 546 & & \\
\hline Primary & & 17.6 & \\
\hline Secondary & & 44.9 & \\
\hline University & & 20.7 & \\
\hline Without & & 16.8 & \\
\hline Husband occupation & 545 & & \\
\hline Without & & 2.9 & \\
\hline Private & & 66.8 & \\
\hline Official of the state & & 30.3 & \\
\hline
\end{tabular}

seroprevalence of hepatitis B and C in pregnant women were 5.9\%, respectively (95\% CI $3.9 \%$ to $8.4 \%$ ) for HBV and $4.1 \%$ (95\% CI 2.5\% to 6.4\%) for antibodies to HCV and 3 women out of 455 were co-infected with both viruses.

For hepatitis B, we observed a strong statistically significant association with the history of tattooing in women during the 12 months preceding the survey OR = 5.8 (95\% CI 2.2 to 14.7) (Table 2). Depending on other variables we did not notice any difference in distribution of the prevalence of $\mathrm{HBV}$, although the prevalence of HBsAg was significantly higher in women with a history of transfusion $(12.5 \%$, OR $=2.3)$ and among women living in couple $(8.2 \%$, OR $=4.2)$. 
Table 2. Prevalence and determinants of HIV, HBV and HCV in pregnant women.

\begin{tabular}{|c|c|c|c|c|c|c|c|c|c|c|c|c|}
\hline & \multicolumn{4}{|c|}{$\mathrm{HIV}+$} & \multicolumn{4}{|c|}{$\mathrm{HBV}+$} & \multicolumn{4}{|c|}{$\mathrm{HCV}+$} \\
\hline & number & $\%$ & OR (IC à 95\%) & $\mathrm{p}$ & number & $\%$ & OR (IC à 95\%) & $\mathrm{p}$ & number & $\%$ & OR (IC à 95\%) & $\mathrm{p}$ \\
\hline Total & 467 & 4.1 & & & 460 & 5.9 & & & 458 & 4.1 & & \\
\hline Age of woman (year) & & & & $0.71^{* *}$ & & & & $0.26^{* *}$ & & & & $0.31^{* *}$ \\
\hline$<20$ & 132 & 2.3 & 1 & & 129 & 7 & 1 & & 130 & 4.6 & 1 & \\
\hline $21-30$ & 195 & 5.6 & $2.5(0.7-11.6)$ & & 192 & 6.3 & $0.8(0.4-2.2)$ & & 190 & 5.3 & $1.1(0.4-3.5)$ & \\
\hline $31-40$ & 115 & 3.5 & $1.5(0.3-8.4)$ & & 114 & 5.3 & $0.7(0.2-2.2)$ & & 113 & 1.8 & $0.4(0.05-1.8)$ & \\
\hline 41 et plus & 23 & 4.3 & $1.9(0.07-19.1)$ & & 23 & 0 & $0.0(0.0-2.2)$ & & 23 & 4.3 & $0.9(0.0-6.7)$ & \\
\hline Marital status & & & & $0.98^{*}$ & & & & $0.23^{*}$ & & & & $0.49^{*}$ \\
\hline Lives couple & 402 & 4.2 & $1.4(0.4-9.0)$ & & 399 & 8.2 & $4.2(0.6-31.4)$ & & 395 & 4.6 & $2.9(0.4-22.6)$ & \\
\hline lives alone & 65 & 3.1 & 1 & & 61 & 3.5 & 1 & & 63 & 1.6 & 1 & \\
\hline Women's studies level & & & & $0.25^{* *}$ & & & & $0.50^{* *}$ & & & & $0.39^{* *}$ \\
\hline Without & 121 & 0.8 & 1 & & 119 & 4.2 & 1 & & 119 & 1.7 & 1 & \\
\hline Primary & 158 & 6.3 & $\begin{array}{c}8.1(1.3- \\
178.9)\end{array}$ & & 154 & 6.5 & $1.6(0.5-5.2)$ & & 154 & 5.8 & $3.6(0.8-24.9)$ & \\
\hline Higher Secondary & 184 & 4.3 & $\begin{array}{c}5.4(0.8- \\
123.0)\end{array}$ & & 183 & 6.6 & $1.6(0.5-5.2)$ & & 180 & 4.4 & $2.7(0.6-18.8)$ & \\
\hline Transfusion last birth & & & & $0.02^{*}$ & & & & $0.14^{*}$ & & & & $0.09^{*}$ \\
\hline Yes & 32 & 15.6 & $4.9(1.5-14.5)$ & & 32 & 12.5 & $2.3(0.7-7.0)$ & & 32 & 12.5 & $3.5(0.9-10.8)$ & \\
\hline Not & 393 & 3.5 & 1 & & 389 & 5.9 & 1 & & 386 & 3.9 & 1 & \\
\hline Tattoo the last 12 months & & & & $0.99^{*}$ & & & & $0.001^{*}$ & & & & $0.38^{*}$ \\
\hline Yes & 33 & 3 & $0.6(0.08-4.8)$ & & 33 & 24.2 & $25.8(2.2-14.7)$ & & 31 & 0 & Unspecified & \\
\hline Not & 376 & 4.8 & 1 & & 371 & 5.1 & 1 & & 371 & 5.1 & 1 & \\
\hline $\begin{array}{c}\text { Original environment of } \\
\text { women }\end{array}$ & & & & 0.09 & & & & 0.27 & & & & $0.09^{*}$ \\
\hline Urban & 100 & 7 & $2.2(0.8-5.8)$ & & 98 & 8.2 & $1.6(0.7-3.8)$ & & 95 & 7.4 & $2.3(0.9-6.1)$ & \\
\hline Rural & 367 & 3.3 & 1 & & 362 & 5.2 & 1 & & 363 & 3.3 & 1 & \\
\hline Husband of instruction & & & & $0.58^{* *}$ & & & & $0.064^{* *}$ & & & & $0.44^{* *}$ \\
\hline Without & 84 & 2.4 & 1 & & 83 & 3.6 & 1 & & 83 & 3.6 & 1 & \\
\hline Primary & 74 & 8.1 & $3.6(0.7-26.6)$ & & 72 & 4.2 & $1.2(0.2-6.9)$ & & 72 & 6.9 & $1.9(0.4-10.4)$ & \\
\hline Secondary & 180 & 5 & $2.1(0.5-14.9)$ & & 177 & 6.2 & $1.7(0.5-8.1)$ & & 176 & 5.1 & $1.4(0.4-6.7)$ & \\
\hline University & 101 & 2 & $0.8(0.08-8.1)$ & & 100 & 10 & $2.9(0.8-13.7)$ & & 99 & 2 & $0.5(0.06-3.7)$ & \\
\hline Husband occupation & & & & $0.08^{*}$ & & & & $0.72^{*}$ & & & & $0.55^{*}$ \\
\hline Without/state's official & 154 & 1.9 & 1 & & 152 & 5.3 & 1 & & 151 & 3.3 & 1 & \\
\hline Private & 293 & 5.4 & $2.9(0.9-12.6)$ & & 286 & 6.6 & $1.3(0.5-3.2)$ & & 284 & 4.9 & $1.4(0.5-4.4)$ & \\
\hline
\end{tabular}

"Fisher's exact test; *'Chi-square trend.

According to hepatitis $\mathrm{C}$ as shown in Table 2, we have not noted a statistical association with the variables studied. Nevertheless, we observed strong associations between HCV and HIV status to certain variables. This was the case for marital status (single versus married: OR = 2.9), blood transfusion history (yes vs no: OR = 3.5), place of residence (urban vs. rural: $\mathrm{OR}=2.3$ ) and the level of education (primary vs without: OR $=3.6$, and 
secondary/tertiary vs without: $\mathrm{OR}=2.7$ ).

\section{Discussion}

In the Democratic Republic of Congo in general and in the province of Maniema, there is very little data on prevalence of hepatitis B and C, mainly in the group of pregnant women. Our study objective was to evaluate the seroprevalence of HBV, HCV and HIV in pregnant women and to determine risk factors. Seroprevalence was $4.1 \%$ for HIV, $5.9 \%$ for HBV and $4.1 \%$ for HCV. HIV seroprevalence found in this study is higher than that provided by the data of the HIV serosurveillance in Maniema province (3.1\%) and estimates of HIV prevalence in pregnant women at the national level (3.5\%) [11]. The difference can be explained by the fact that our survey was conducted in the general population as the two results (national and serosurveillance) are in sentinel sites used by pregnant women. Our HIV prevalence is lower than that observed in studies conducted in Pointe Noire (7.6\%) and Ethiopia (6.6\%) [1] [12]. HIV prevalence among pregnant women appears to be a good reflection of the prevalence in the general population in the latter two countries, the overall prevalence is also higher than that of the DRC.

In our study the risk factor significantly associated with HIV-positive pregnant women had a recent history of blood transfusion as have mounted other studies [1] [12]-[15]. This again puts in evidence the whole problem of the high risk faced by recipients of blood products in Sub-Saharan Africa. [16] Maniema is a province of the DRC in poorer health infrastructure, especially those involved in blood safety.

The surface antigen of hepatitis B is a good marker to evaluate the prevalence of hepatitis B in the population [10] [17]. In our study we found a prevalence lower than of countries located in highly endemic area. It is less than that found in Pointe Noire but is approaching found in studies in Tunisia and in certain African Arab countries that are part of medium-prevalence countries [1] [2] [18] [19]. It still remains far higher than the prevalence found in some Western countries such as France (0.54\%) [20] and Spain [21] (0.1\%). Despite the low frequency of HBsAg in our series compared to other African series, porting of HBsAg in pregnant women remains a concern especially if one knows that any woman with HIV can transmit HBV HBsAg its child throughout the pregnancy as in the perinatal period [3] [17] [22]. This fear persists especially as screening for viral marker that is not systematically conducted in antenatal clinics in our country. Our study showed tattooing or scarification as the main risk factor. This risk factor (tattoo) was also found in studies in Mali and Ethiopia [12] [17].

The seroprevalence of hepatitis $\mathrm{C}$ was $4.1 \%$ in our study, but no statistically significant association was observed with the factors considered while most studies of risk factors for hepatitis $\mathrm{C}$ in pregnant women or in another group showed some relation to history or tattoo, or blood transfusion, or abortion [1] [19] [23] [24].

The difference between our results and those of other studies on the prevalence of HIV, HBV and HCV and in the detection of certain risk factors of these viruses could be explained in part by differences in the characteristics anthropometric and socio-cultural populations studied and partly by methodological differences. Our study its purpose because it had set a goal to make an inventory on the seroprevalence of these three viruses in the group of pregnant women in the province of Maniema.

\section{Conclusion}

This study showed that the three viruses HIV (4.1\%), HBV (5.9\%) and HCV (4.1\%) are frequent in the group of pregnant women and remain a public health problem. Like what is done in the HIV control program to reduce transmission from mother to child, all pregnant women should be screened for HBV and HCV during prenatal consultations. As in other studies, we identified a history of blood transfusion as a risk factor for HIV infection and body tattoo as a risk factor for HBV infection. This implies that the organization of blood transfusion services should be enhanced by systematic screening of these markers for the whole blood bag to ensure safe blood transfusion recipients. To this must be added a health education about the modes of transmission of these viruses in the general population and especially among women.

\section{References}

[1] Bossali, F., Taty-Taty, R., Houssissa, P., N’suele, W., Lingouala, L.G., Ontsira, E.N. and Obengui (2012) Seroprevalence of Co-Infection, Hepatitis B, Hepatitis C and HIV among Expectant Mothers Maternity Adolphe Sice Hospital of Pointe-Noire in 2010. Journal Africain d'Hépato-Gastroentérologie, 6, 315-319.

http://dx.doi.org/10.1007/s12157-012-0424-1 
[2] Hannachi, N., Bahri, O., Mhalla, S., Marzouk, Mr., Sadraoui, A., Belguith, A., Triki, H. and Boukadida, J. (2009) Viral Hepatitis B among Tunisian Pregnant Women: Risk Factors and Interests the Study of Viral Replication in Case of HBe-Antigen Negative. Pathology Biology, 57, e43-e47.

[3] Store-Rogez, S. and Alain Denis, F. (2002) Hepatitis Viruses: MTCT. Pathologie Biologie, 50, 568-575.

[4] Debbeche, R., Said, Y., Ben Temime, H., El Jery, K., Salem, S.B.M. and Najjar, T. (2013) Hepatitis C Epidemiology in Tunisia. The Tunisia Medical, 91, 86-91.

[5] Lavanchy, D. (2009) The Global Burden of Hepatitis C. Liver International, 29, 74-81. http://dx.doi.org/10.1111/j.1478-3231.2008.01934.x

[6] Shepard, C.W., Finelli, L. and Alter, M.J. (2005) Global Epidemiology of Hepatitis C Virus Infection. Lancet Infectious Diseases, 5, 558-567. http://dx.doi.org/10.1016/S1473-3099(05)70216-4

[7] Denis, F., Ranger-Rogez, S., Tabaste, J.L., Soulie, J.C. and Goudeau, A. (1999) Hepatitis B. In: Enis, F., Ed., Transmitted the Virus from Mother to Child, John Libbey Eurotext, Paris, 85-103.

[8] Otta, J.J., Stevensa, G.A., Groegerb, J. and Wiersmaa, S.T. (2012) Global Epidemiology of Hepatitis B Virus Infection: New Estimates of Age-Specific and HBsAg Seroprevalence Endemicity. Vaccine, 30, 2212-2219. http://dx.doi.org/10.1016/j.vaccine.2011.12.116

[9] Hanafiah, K.M., Groeger, J., Flaxman, D.A. and Wiersma, S.T. (2013) Global Epidemiology of Hepatitis C Virus Infection: New Estimates of Age Specific-Antibody to HCV Seroprevalence. Hepatology, 57, 1333-1342. http://dx.doi.org/10.1002/hep.26141

[10] Nzaji, K. and Kabyla Ilunga, B. (2013) Prevalence of Infectious Markers in Rural Blood Donors. Cas General Hospital Kamina Reference. Public Health, 25, 213-217.

[11] National AIDS Control Plan 2014-2017. Ministry of Health DRC 2013, Kinshasa.

[12] Zenebe, Y., Mulu, W., Yimer, M. and Abera, B. (2014) Sero-Prevalence and Risk Factors of Hepatitis B Virus and Human Immunodeficiency Virus Infection among Pregnant Women in Bahir Dar city, Northwest Ethiopia: A Cross Sectional Study. BMC Infectious Diseases, 14, 118.

[13] Roberts, E.A. and Yeung, L. (2002) Maternal-Infant Transmission of Hepatitis C Virus Infection. Hepatology, 36, S106-S113. http://dx.doi.org/10.1002/hep.1840360714

[14] Mast, E.E., Hwang, L.Y., Seto, D.S.Y., Nolte, F.S., Nainan, O.V., Wurtzel, H. and Alter, M.J. (2005) Risk Factoring for Perinatal Transmission of Hepatitis C Virus (HCV) and the Natural History of HCV Infection Acquired in Infancy. The Journal of Infectious Diseases, 192, 1880-1889. http://dx.doi.org/10.1086/497701

[15] Larsen, C., Pialoux, G. and Salmon, D. (2005) Prevalence of Co-Infection by the Hepatitis B and C in HIV Population of France. BEH, 23, 109-112.

[16] Tagny, C.T., Mbanya, D., Tapko, J.B. and Lefrère, J.J. (2008) Blood Safety in Sub-Saharan Africa: A Multi-Factorial Problem. Transfusion, 48, 1256-1261. http://dx.doi.org/10.1111/j.1537-2995.2008.01697.x

[17] Sidibe, S., Sacko, B.Y. and Traoré, I. (2001) Prevalence of Serological Markers of Hepatitis B in Pregnant Women in the District of Bamako, Mali. Bulletin de la Société de pathologie Exotique, 84, 339-341.

[18] Triki, H., Said, N., Salah, A.B., Arrouji, A., Ahmed, F.B., Bouguerra, A., Hmida, S., Dhahri, R. and Dellagi, K. (1997) Seroepidemiology of Hepatitis B, C and Delta Viruses in Tunisia. Transactions of the Royal Society of Tropical Medicine and Hygiene, 91, 11-14. http://dx.doi.org/10.1016/S0035-9203(97)90374-6

[19] Gasim, G.I., Murad, I.A. and Adam, I. (2013) Hepatitis B and C Virus Infections among Pregnant Women in Arab and African Countries. The Journal of Infection in Developing Countries, 7, 566-578. http://dx.doi.org/10.3855/jidc.3243

[20] François, D., Berges, P., Chastagner, M. and Delpeyroux, C. (2003) Screening HBsAg in Pregnant Women: What Coverage? Survey in Haute-Vienne. BEH, 33, 157-160.

[21] Salleras, L., Domínguez, A., Bruguera, M., Plans, P., Espuñes, J., Costa, J., et al. (2009) Hepatitis B Seroepidemiology of Virus Infection in Pregnant Women in Catalonia (Spain). Journal of Clinical Virology, 44, 329-332. http://dx.doi.org/10.1016/j.jcv.2009.01.002

[22] Wong, F., Pai, R., Van Schalkwyk, J. and Yoshida, E.M. (2014) Hepatitis B in Pregnancy: A Concise Review of Neonatal Vertical Transmission and Antiviral Prophylaxis. Annals of Hepatology, 13, 187-195.

[23] Merle, V., Goria, O., Gourier-Frery, C., Benguigui, C., Michel, P., Huet, P., et al. (1999) Risk Factors of Contamination by Hepatitis C Virus. Case-Control Study in the General Population. Gastroenterologie Clinique et Biologique, 23, 439-446.

[24] Olokoba, A.B., Accama, L.A., Gashau, W. and Salawu, F.K. (2011) Risk Factoring and Clinical Presentation of Hepatitis C Virus Infection in Nigerians with Chronic Liver Disease. Tropical Doctor, 41, 146-147.

http://dx.doi.org/10.1258/td.2011.100378 